Acta med. scand. Vol. 195, pp. 397-401, 1974

\title{
THE EFFECT OF PROPRANOLOL ON PLASMA RENIN ACTIVITY AND BLOOD PRESSURE IN MILD ESSENTIAL HYPERTENSION
}

\author{
Lennart Hansson ${ }^{1}$ and Andrew J. Zweifler \\ From the Department of Internal Medicine, Hypertension Section, University of Michigan Medical Center, \\ Ann Arbor, Michigan, USA
}

\begin{abstract}
Fourteen male patients with mild to moderate essential hypertension have been studied with regard to plasma renin activity (PRA) after acute and prolonged $\beta$ adrenergic blockade with propranolol. Initial PRA was determined after four weeks of placebo treatment. Before propranolol was given PRA rose in response to $10 \mathrm{~min}$ of $45^{\circ}$ head-up tilt from $151.7 \mathrm{ng} / 100 \mathrm{ml} / \mathrm{h}$ to $248.7 \mathrm{ng} / 100 \mathrm{ml} / \mathrm{h}$ $(p<0.01)$. After acute administration of propranolol 0.22 $\mathrm{mg} / \mathrm{kg}$ b.wt. i.v. and following repeated tilt for $10 \mathrm{~min}$ PRA only rose to $204.7 \mathrm{ng} / 100 \mathrm{ml} / \mathrm{h}$ (n.s.). Following four weeks of oral propranolol treatment at $160-320 \mathrm{mg}$ daily PRA after tilt was $39.0 \mathrm{ng} / 100 \mathrm{ml} / \mathrm{h}$. Thus a significant reduction of PRA had taken place $(p<0.005)$ to a level constituting only $15 \%$ of the initial PRA after tilt.

The reduction of blood pressure (BP) after four weeks of propranolol treatment was also significant. Diastolic BP was reduced by $19 \mathrm{~mm} \mathrm{Hg}(p<0.001)$. The changes in BP and tilted PRA were not significantly correlated $(r=0.449, p<0.10)$. These results indicate that propranolol causes a marked reduction of PRA in addition to its hypotensive effect. However, this does not necessarily imply that there is a direct causal relationship between the effect of propranolol on PRA and its effect on BP.
\end{abstract}

Usually, renin is not elevated in patients with nonmalignant essential hypertension $(7,12,29)$ and aldosterone secretion is normal $(7,19)$. On the other hand, elevated renin levels and increased aldosterone secretion practically always occur in malignant hypertension $(16,17,20)$. Already in 1960 Laragh et al. suggested that the vascular damage seen in malignant hypertension was related to elevated levels of angiotensin $(16,17)$. Later animal studies have shown that excess renin/angiotensin may cause vascular lesions of the same appearance as those seen in malignant hypertension $(5,8,9,22)$.

Recently Laragh's group presented observations on 219 hypertensive patients followed for 10 years,

1 Present address: Department of Internal Medicine I, Sahlgren's Hospital, University of Göteborg, Göteborg, Sweden. which indicated that low plasma renin was associated with a reduced risk of cardiovascular complications such as stroke and myocardial infarction (2). Others do not support this view (6).

Based on observations by Laragh and coworkers (2), it would be logical to use antihypertensive therapy that not only reduces blood pressure (BP) but also lowers renin actively. Several of the antihypertensive drugs have been studied with regard to their effect on plasma renin activity (PRA).

Thus diuretics $(1,28)$, hydralazine (21), diazoxide (15) and sodium nitroprusside (14) have been shown to cause elevations of PRA, while drugs with adrenergic inhibitory effects may cause mild to moderate reductions of PRA. This has been demonstrated e.g. for methyldopa (23), clonidine (13, $24)$, phentolamine (30), propranolol (30) and alprenolol (4).

As propranolol, at least in acute experiments, seems to be quite effective in reducing PRA (3) and as the experience with propranolol in hypertension has been encouraging $(11,26,31)$ the present study was designed to study the effect on PRA of acute and chronic $\beta$-adrenergic blockade with propranolol in patients with essential hypertension.

\section{MATERIAL}

Fourteen male patients, 11 Caucasian, 3 Black, with mild to moderate essential hypertension were studied. Their average age was 45 years (range 27-66). Further details on the patients are recorded in Table I. Secondary causes for hypertension were excluded (physical examination, rapid sequence urograms or renal arteriograms, serum electrolytes and urinary catecholamines and aldosterone). Finally, patients with a history of bronchial asthma or cardiac failure were not included in the study. 
Table I. Patient information

\begin{tabular}{|c|c|c|c|c|c|c|}
\hline $\begin{array}{l}\text { Pat. } \\
\text { no. }\end{array}$ & $\begin{array}{l}\text { Age } \\
(y .)\end{array}$ & Race $^{a}$ & $\begin{array}{l}\text { Eye } \\
\text { grounds }{ }^{b}\end{array}$ & $\begin{array}{l}\text { Serum } \\
\text { creatinine } \\
(\mathrm{mg} / 100 \\
\mathrm{ml})\end{array}$ & $\mathrm{LVH}^{c}$ & $\begin{array}{l}\text { Initial } \\
\mathrm{BP}^{d} \\
(\mathrm{mmHg})\end{array}$ \\
\hline 1 & 50 & C & I & 0.9 & - & $159 / 98$ \\
\hline 2 & 50 & B & II & 1.1 & - & $150 / 110$ \\
\hline 3 & 55 & B & I & 1.0 & - & $155 / 110$ \\
\hline 4 & 53 & C & I & 1.0 & - & $180 / 120$ \\
\hline 5 & 66 & C & I & 1.2 & - & $169 / 86$ \\
\hline 6 & 40 & C & II & 1.6 & - & $174 / 137$ \\
\hline 7 & 27 & B & 0 & 1.1 & - & $134 / 95$ \\
\hline 8 & 52 & C & I & 0.9 & - & $155 / 108$ \\
\hline 9 & 49 & C & II & 1.1 & + & $200 / 128$ \\
\hline 10 & 45 & $\mathrm{C}$ & II & 1.2 & - & $161 / 111$ \\
\hline 11 & 44 & C & I & 1.0 & - & $177 / 107$ \\
\hline 12 & 41 & C & II & 1.1 & + & $184 / 105$ \\
\hline 13 & 43 & C & II & 1.0 & - & $140 / 96$ \\
\hline 14 & 35 & $\mathrm{C}$ & II & 0.9 & - & $162 / 110$ \\
\hline
\end{tabular}

${ }^{a} \mathrm{C}=$ Caucasian, $\mathrm{B}=$ Black.

${ }^{b}$ Keith, Wagener and Barker classification.

c Left ventricular hypertrophy in ECG or chest X-ray.

d Measured after $15 \mathrm{~min}$ recumbency in the clinic following 4 weeks of placebo treatment.

\section{METHODS}

After informed consent was obtained, all patients were given placebo as the only treatment for four weeks. They were then admitted to the Clinical Research Unit for four days. During these days baseline laboratory studies were performed. A no-added-salt diet $(<180 \mathrm{mEq} \mathrm{Na}$ daily) was introduced in order to avoid excessive salt intake and the patients were instructed daily by a dietician regarding the continuation of this diet following discharge from the hospital.

On the morning of the fourth day the initial samples for PRA determinations were drawn. A catheter was placed in the left brachial artery with the patient in the resting recumbent position. After approximately $45 \mathrm{~min}$ of rest the first blood sample was drawn. The patients were then tilted to a $45^{\circ}$ head-up position for $10 \mathrm{~min}$ and a second blood sample was drawn.

After recumbency had been regained for a period of $\mathbf{4 5}$ min, propranolol was administered i.v. $0.22 \mathrm{mg} / \mathrm{kg}$ b.wt. Following a repeated $10-\mathrm{min}$ period of tilt a third blood sample was drawn.

The patients were then discharged with propranolol orally $40 \mathrm{mg}$ four times daily. They were advised to continue the no-added-salt diet. After two weeks propranolol was either increased to $80 \mathrm{mg}$ four times daily or kept unchanged (if a diastolic BP reduction of $15 \mathrm{mmHg}$ or more was recorded). The average daily dosage of propranolol during weeks three and four was $250 \mathrm{mg}$.

The fourth sample for PRA determination was collected after four weeks of oral propranolol treatment using the same set-up and under identical conditions as during the initial sampling. The fourth arterial sample was drawn after 10 min of tilt.

\section{Blood pressure measurements}

Office BPs were recorded by the same two nurses throughout the study. Their correlation was checked frequently by simultaneous readings using a " $Y$ " connection. Readings were always at the same time of day in the recumbent position after $15 \mathrm{~min}$ rest in a quiet air-conditioned room. Phase $V$ (disappearance) of Korotkoff sounds was taken as the diastolic endpoint.

\section{Analysis of plasma renin activity}

For each sample $10 \mathrm{ml}$ arterial blood was collected in a prechilled tube containing approximately $10 \mathrm{mg}$ EDTA-Na. The tube was immediately placed in ice and centrifuged within $20 \mathrm{~min}$ in a refrigerated centrifuge to recover the plasma. The plasma samples were then frozen and stored until all samples were collected. For analysis a radioimmunoassay technique was used $(10,27)$ by which PRA is determined by measuring the generated angiotensin I (Schwartz/Mann, Orangeburg, N.Y.). Duplicate analyses were made of all specimens and the results were compared to a standard curve obtained from standard solutions of angiotensin I. Nonspecific activity was determined in specimen no. 1 and subtracted from specimen nos. 1-3 and again determined and subtracted from specimen no. 4. The error of duplicate determinations varied between $4.2 \%$ and $7.9 \%$.

Urinary sodium excretion

A 24-hour urine collection, ending on the morning of the fourth day, was made for determination of sodium excretion.

\section{Assessment of $\beta$-adrenergic blockade}

Infusion of i.v. isoproterenol, $3 \mu \mathrm{g} / \mathrm{min}$ for $3 \mathrm{~min}$, was used for estimation of the degree of $\beta$-adrenergic blockade. The change of heart rate was calculated from a continuous ECG tracing. This test was performed in all patients in the initial untreated state and was repeated after acute i.v. as well as after chronic oral administration of propranolol.

\section{RESULTS}

Table II presents the individual results regarding PRA in the initial untreated state and after acute and chronic $\beta$-adrenergic blockade with propranolol as well as sodium excretion and change of diastolic pressure. The average resting PRA was $151.7 \mathrm{ng} / 100$ $\mathrm{ml} / \mathrm{h}$ and rose to $248.7 \mathrm{ng} / 100 \mathrm{ml} / \mathrm{h}$ after $10 \mathrm{~min}$ of tilt $(p<0.01)$. Renewed tilt after i.v. propranolol produced a smaller increase of PRA to $204.7 \mathrm{ng} / 100$ $\mathrm{ml} / \mathrm{h}$ (n.s.).

After four weeks of oral propranolol, PRA after $10 \mathrm{~min}$ of tilt was $39.0 \mathrm{ng} / 100 \mathrm{ml} / \mathrm{h}$. This is significantly lower than both the initial recumbent PRA $(p<0.005)$ and the initial tilted PRA $(p<0.005)$ (Fig. 1). Expressed as \% of the corresponding initial tilted PRA the level after four weeks of oral propranolol was reduced by $85 \%$. 
Table II. Plasma renin activity $(\mathrm{ng} / 100 \mathrm{ml} / \mathrm{h})$, sodium excretion $(\mathrm{mEq} / 24 \mathrm{~h})$ and blood pressure reduction $(\mathrm{mmHg})$

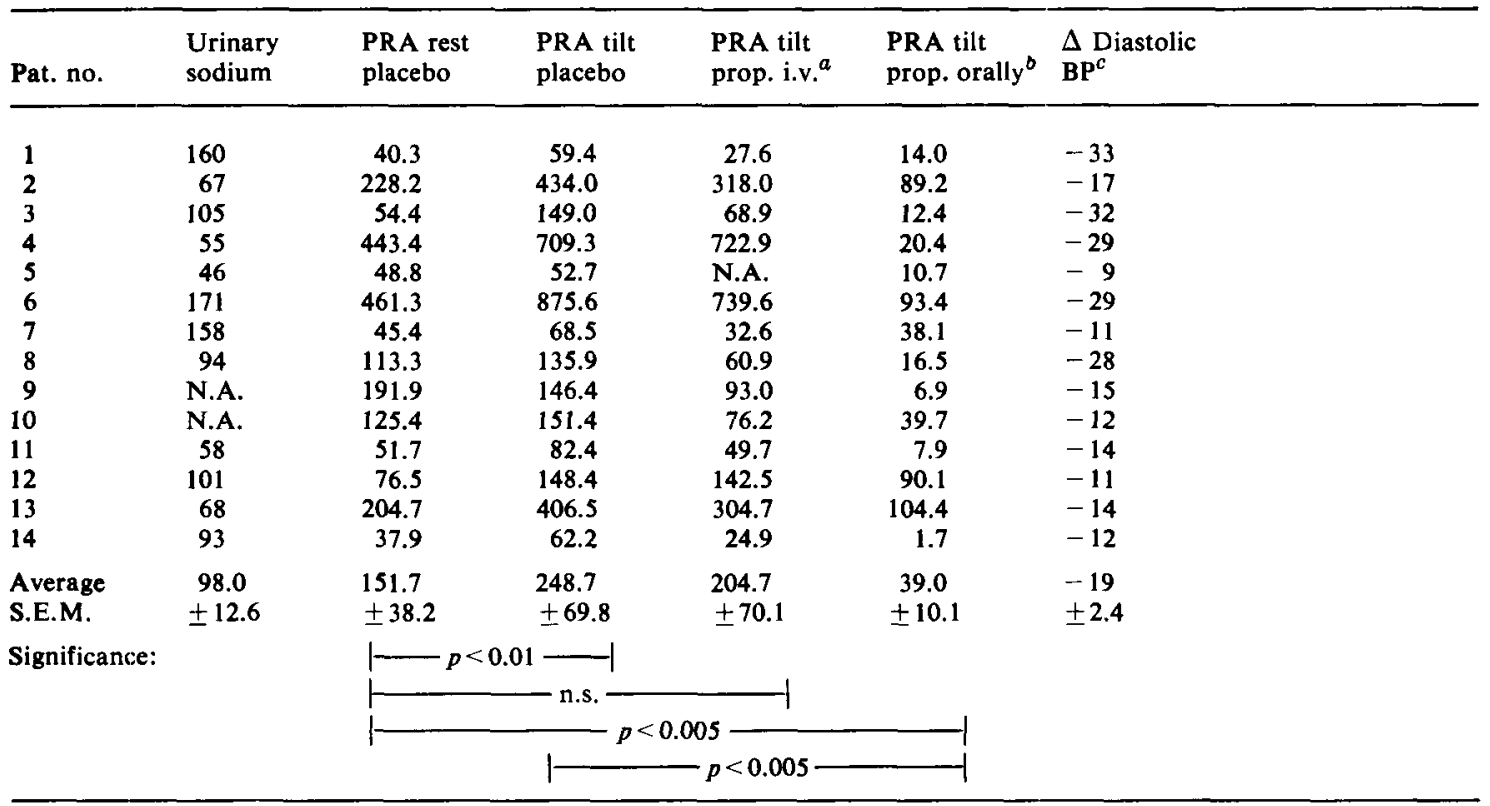

a Propranolol $0.22 \mathrm{mg} / \mathrm{kg}$.

b Propranolol for four weeks, $160-320 \mathrm{mg}$ daily.

c Change after four weeks of oral propranolol treatment.

N.A. $=$ not available.

Recumbent resting BP also fell in all patients as can be seen in Table II. The average drop of diastolic BP was $19 \mathrm{mmHg}(p<0.001)$.

The change of PRA from the initial tilted position to tilt after four weeks of oral propranolol was not significantly correlated to the reduction of diastolic BP $(r=0.449, p<0.10)$.

That clinically significant $\beta$-adrenergic blockade was obtained both after i.v. and oral propranolol is illustrated by the effect of isoproterenol infusions. During placebo treatment the heart rate rose from 73 to 112 beats/min $(p<0.001)$. After i.v. propranolol repeated infusion of isoproterenol increased heart rate from 66 to 67 beats $/ \mathrm{min}$ and following four weeks of oral propranolol isoproterenol infusion increased the heart rate from 57 to 62 beats/min.

\section{DISCUSSION}

It has previously been demonstrated that acute administration of propranolol can prevent or reduce an expected rise of PRA in response to upright posture (30). On the other hand Castenfors et al. (4), using chronic administration of alprenolol to- gether with chlorthalidone, found that although PRA was reduced both in the recumbent and erect position the orthostatic increase of PRA was not abolished. We cannot exclude the possibility of a small increase of PRA due to tilt after acute or prolonged $\beta$-blockade as recumbent PRA was not measured after propranolol, but clearly any such increase must have been minute.

The effects of chronic oral administration of propranolol are quite striking, causing a marked reduction of PRA. Thus, comparing PRA after tilt in the untreated state and after oral propranolol it can be seen that PRA after chronic $\beta$-adrenergic blockade is only $15 \%$ of the initial level. Absolute final values in individual patients were either low or exceptionally low. The poor correlation between reduction of PRA and reduction of BP may be due to the fact that, although PRA fell drastically in all patients, the BP change was variable within the group. For this reason we cannot support the hypothesis of Bühler et al. (3) that induced change in PRA is a primary factor underlying the antihypertensive effect of $\beta$-adrenergic blockade.

It should be pointed out, though, that a direct 


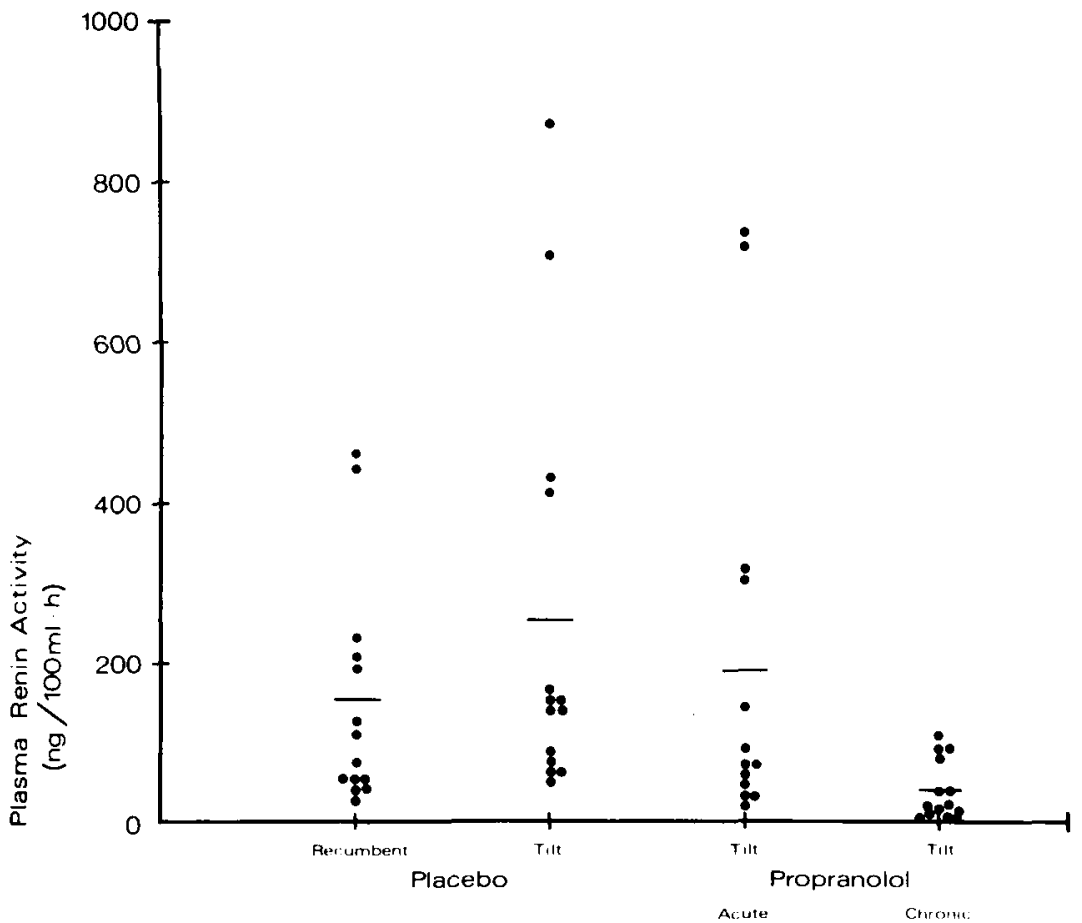

Fig. 1. PRA in 14 patients with essential hypertension. Placebo $=$ measurements after 4 weeks of placebo treatment. Recumbent $=$ horizontal rest for at least $45 \mathrm{~min}$. Tilt $=45^{\circ}$ head-up tilt for $10 \mathrm{~min}$. Acute Propranolol $=0.22 \mathrm{mg} / \mathrm{kg}$ b.wt. i.v. Chronic Propranolol= oral treatment for 4 weeks with 160-320 mg daily.

PRA after tilt during placebo is significantly higher than in the recumbent position $(p<0.01)$. PRA after chronic propranolol is significantly lower than after placebo both when compared to the recumbent value $(p<0.005)$ and the tilted value $(p<0.005)$ (paired $t$-test). comparison with the results of Bühler et al. is not possible as different methods were used for analysing PRA. Furthermore, our conclusions are based on stimulated (tilted) PRA and confined to patients with mild essential hypertension. Likewise, although low PRA hypertensives as a group did not respond as well to propranolol as those with normal PRA, the variability of this phenomenon was such that we found it to be statistically insignificant. Finally, the dosage of propranolol was almost twice as high in the present study in comparison with the study of Bühler et al. Our interpretation of these results is tempered by the fact that the number of patients in this study was relatively small and that none had renovascular hypertension or a remarkably high initial PRA.

The rapid changes of PRA following change of posture that were observed in the present study confirm previous results by others (25). Finally, sodium excretion was not studied at the end of four weeks of propranolol therapy. However, as the patients were instructed by a dietician to maintain a "normal" diet and to avoid excess salt intake, it is not logical to assume that the observed drastic changes of PRA were significantly influenced by possible minor variations of salt intake.

Regardless of its effect on BP, it is clear that chronic administration of propranolol induces a low renin state. The clinical importance of this finding, i.e. its relation to the potential reduction of cardiovascular complications to hypertension (2), deserves further investigation.

\section{ACKNOWLEDGEMENTS}

This work was supported by Michigan Heart Association, Ayerst Laboratories (Dr R. G. Mazlen, MD), USPHS grant 5-M01-RR-42 and 2-P11-GM-15559 and the Swedish National Society against Heart and Chest Diseases. L. Hansson was the recipient of a travel grant from the Swedish Medical Research Council, K71-19R-3442.

\section{REFERENCES}

1. Bourgoignie, J. J., Catanzano, F. J. \& Perry, H. M., Jr: Renin-angiotensin-aldosterone system during chronic thiazide therapy of benign hypertension. Circulation 37: 27, 1968.

2. Brunner, H. R., Laragh, J. H., Baer, L., Newton, M. A., Goodwin, F. T., Krakoff, L. R., Bard, R. H. \& Bühler, F. R.: Essential hypertension: Renin and aldosterone, heart attack and stroke. New Engl. J. Med. 286: 441, 1972.

3. Bühler, F. R., Laragh, J. H., Baer, L., Vaughan, E. D. \& Brunner, H. R.: Propranolol inhibition of renin secretion. New Engl. J. Med. 287: 1209, 1972.

4. Castenfors, J., Johnsson, H. \& Orö, L.: Effect of alpre- 
nolol on blood pressure and plasma renin activity in hypertensive patients. Acta med. scand. 193: 189, 1973.

5. Cuthbert, M. F. \& Peart, W. S.: Studies on the identity of a vascular permeability factor of renal origin. Clin. Sci. 38: 309, 1970.

6. Doyle, A. E., Jerums, G., Johnston, C. I. \& Louis, W. J.: Plasma renin levels and vascular complications in hypertension. Brit. med. J. 1: 206, 1973.

7. Fasciolo, J. C., DeVito, E., Romero, J. C. \& Cucchi, J. N.: The renin content of the blood of humans and dogs under several conditions. Canad. med. Ass. J. 90: 206, 1964.

8. Gavras, H., Brown, J. J., Lever, A. F., MacAdam, R. F. \& Robertson, J. I. S.: Acute renal failure, tubular necrosis and myocardial infarction induced in the rabbit by intravenous angiotensin II. Lancet 2: 19, 1971.

9. Giese, J.: Acute hypertensive vascular disease: I. Relation between blood pressure changes and vascular lesions in different forms of acute hypertension. Acta path. microbiol. scand. 62: 481, 1964.

10. Haber, E., Koerner, T., Page, L. B., Kliman, B. \& Purnode, A.: Application of a radioimmunoassay for angiotensin I to the physiologic measurements of plasma renin activity in normal human subjects. J. clin. Endocr. 29: 1349, 1969.

11. Hansson, L., Malmcrona, R., Olander, R., Rosenhall, L., Westerlund, A., Áberg, H. \& Hood, B.: Propranolol in hypertension. Report on 158 patients treated up to one year. Klin. Wschr. 50: 364, 1972.

12. Helmer, O. M.: Renin activity in blood from patients with hypertension. Canad. med. Ass. J. 90: 221, 1964.

13. Hökfєlt, B., Hedeland, H. \& Dymling, J. F.: Studies on catecholamines, renin and aldosterone following Catapresan ${ }^{\otimes}$ (2-(2.6-dichlor-phenylamine)-2-imidazoline hydrochloride) in hypertensive patients. Europ. J. Pharmacol. 10: 389, 1970.

14. Kaneko, Y., Ikeda, T., Takeda, T. \& Ueda, H.: Renin release during acute reduction of arterial pressure in normotensive subjects and patients with renovascular hypertension. J. clin. Invest. 46: 705, 1967.

15. Küchel, O., Fishman, L. M., Liddle, G. W. \& Michalis, A.: Effect of diazoxide on plasma renin activity in hypertensive patients. Ann. intern. Med. 67: 791, 1967.

16. Laragh, J. H.: The role of aldosterone in man: Evidence for regulation of electrolyte balance and arterial pressure by a renal-adrenal system which may be involved in malignant hypertension. J.A.M.A. 174: 293, 1960.

17. Laragh, J. H., Angers, M., Kelley, W. G. \& Liebermann, S.: Hypotensive agents and pressor substances: The effect of epinephrine, norepinephrine, angiotensin II and others on the secretory rate of aldosterone in man. J.A.M.A. 174: 234, 1960.
18. Laragh, J. H., Baer, L., Brunner, H. R., Bühler, F. R., Sealey, J. E. \& Vaughan, E. D., Jr: Renin, angiotensin and aldosterone system in pathogenesis and management of hypertensive vascular disease. Amer. J. Med. 52: 633, 1972.

19. Laragh, J. H., Sealey, J. E. \& Sommers, S. C.: Patterns of adrenal secretion and urinary excretion of aldosterone and plasma renin activity in normal and hypertensive subjects. Circulat. Res., Suppl. 1: 158, 1966.

20. Laragh, J. H., Ulich, S., Januszewicz, V., Deming, Q. B., Kelly, W. G. \& Liebermann, S.: Aldosterone secretion in primary and malignant hypertension. J. clin. Invest. 39: $1091,1960$.

21. Mannik, J. A., Huvos, A. \& Hollander, W. E.: Posthydralazine renin release in the diagnosis of renovascular hypertension. Ann. Surg. 70: 409, 1969.

22. Masson, G. M. C., Mikasa, A. \& Yasuda, H.: Experimental vascular disease elicited by aldosterone and renin. Endocrinology 71: 505, 1962.

23. Mohammed, S., Fasola, A. F., Privitera, P. J., Lipicky, R. J., Martz, B. L. \& Gaffney, T. E.: Effect of methyldopa on plasma renin activity in man. Circulat. Res. 25: 543, 1969.

24. Onesti, G., Schwartz, A. B., Kim, K. E., Paz-Martinez, V. \& Swartz, O.: Antihypertensive effect of clonidine. Circulat. Res., Suppl. 2: 53, 1971.

25. Oparil, S., Vassaux, C., Sanders, C. A. \& Haber, E.: Role of renin in acute postural homeostasis. Circulation 41: 89, 1970.

26. Prichard, B. N. P. \& Gillam, P. M. S.: Treatment of hypertension with propranolol. Brit. med. J. 1: 7, 1969.

27. Stockigt, J. R., Collins, R. D. \& Biglieri, E. G.: Determination of plasma renin concentration by angiotensin I immunoassay. Circulat. Res., Suppl. 2: 175, 1971.

28. Tarazi, R. C., Dustan, H. P. \& Frohlich, E. D.: Longterm thiazide therapy in essential hypertension. Evidence for persistent alteration in plasma volume and renin activity. Circulation 41: 709, 1970.

29. Veyrat, R., DeChamplain, J., Boucher, R. \& Genest, J.: Measurement of human arterial renin activity in some physiological and pathological states. Canad. med. Ass. J. 90: $215,1964$.

30. Winer, N., Chokshi, D. S., Yoon, M. S. \& Freedman, A. D.: Adrenergic receptor mediation of renin secretion. J. clin. Endocrin. 29: 1168, 1969.

31. Zacharias, F. J., Cowen, K. J., Prestt, J., Vickers, J. \& Wall, B. G.: Propranolol in hypertension: A study of long-term therapy 1964-1970. Amer. Heart J. 83: 755, 1972. 